Tetzner, Julia; Becker, Michael

\title{
Why are you so optimistic? Effects of sociodemographic factors, individual experiences and peer characteristics on optimism in early adolescents
}

formal und inhaltlich überarbeitete Version der Originalveröffentlichung in:

formally and content revised edition of the original source in:

Journal of personality 87 (2019) 3, S. 661-675, 10.1111/jopy. 12424

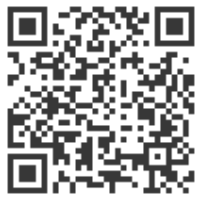

Bitte verwenden Sie in der Quellenangabe folgende URN oder DOI /

Please use the following URN or DOI for reference:

urn:nbn:de:0111-dipfdocs-190638

10.25657/02:19063

https://nbn-resolving.org/urn:nbn:de:0111-dipfdocs-190638

https://doi.org/10.25657/02:19063

\section{Nutzungsbedingungen}

Gewährt wird ein nicht exklusives, nicht übertragbares, persönliches und beschränktes Recht auf Nutzung dieses Dokuments. Dieses Dokument is ausschließlich für den persönlichen, nicht-kommerziellen Gebrauch bestimmt. Die Nutzung stellt keine Übertragung des Eigentumsrechts an diesem Dokument dar und gilt vorbehaltlich der folgenden Einschränkungen: Auf sammtlichen Kopien dieses Dokuments müssen alle Urheberrechtshinweise und sonstigen Hinweise auf gesetzlichen Schutz beibehalten werden. Sie dürfen dieses Dokument nicht in irgendeiner Weise abändern, noch dürfen Sie dieses Dokument für öffentliche oder kommerzielle Zwecke vervielfältigen, öffentlich ausstellen, aufführen, vertreiben oder anderweitig nutzen.

Mit der Verwendung dieses Dokuments erkennen Sie die Nutzungsbedingungen an.

\section{Terms of use}

We grant a non-exclusive, non-transferable, individual and limited right to using this document.

This document is solely intended for your personal, non-commercial use. Use of this document does not include any transfer of property rights and it is conditional to the following limitations: All of the copies of this documents must retain all copyright information and other information regarding legal protection. You are not allowed to alter this document in any way, to copy it for public or commercial purposes, to exhibit the document in public, to perform, distribute or otherwise use the document in public.

By using this particular document, you accept the above-stated conditions of use.

\section{Kontakt / Contact:}

DIPF | Leibniz-Institut für

Bildungsforschung und Bildungsinformation

Frankfurter Forschungsbibliothek

publikationen@dipf.de

www.dipfdocs.de

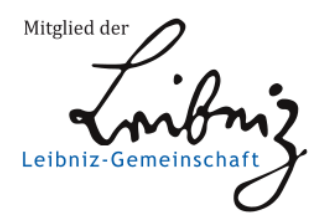


This is the peer reviewed version of the following article: Tetzner, Julia / Becker, Michael: Why are you so optimistic? Effects of sociodemographic factors, individual experiences and peer characteristics on optimism in early adolescents. Journal of personality, 87(3), pp. 661-675, which has been published in final form at doi.org/10.1111/jopy.12424. This article may be used for non-commercial purposes in accordance with Wiley Terms and Conditions for SelfArchiving. 


\title{
Why are you so optimistic? Effects of sociodemographic factors, individual experiences, and peer characteristics on optimism in early adolescents
}

\author{
Julia Tetzner ${ }_{1}$, Michael Becker ${ }_{1,2}$ \\ ${ }_{1}$ Leibniz Institute for Research and Information in Education, Germany \\ ${ }_{2}$ Leibniz Institute for Science and Mathematics Education, Germany
}

Correspondence concerning this article should be addressed to Julia Tetzner, German Institute

for International Educational Research, Warschauer Straße 34-38, 10243 Berlin, Germany. Email: tetzner@dipf.de

Acknowledgements:

We are grateful to the team of the BIJU study and, in particular, to the principal investigators of the BIJU study, Jürgen Baumert, Olaf Köller, and Kai S. Cortina for allowing us to use the dataset.

This article version has been accepted for publication in Journal of Personality and undergone full peer review but has not been through the copyediting, typesetting, pagination and proofreading process, which may lead to differences between this version and the published version. The final, definitive version of this paper has been published in:

Tetzner, J., \& Becker, M. (2019). Why are you so optimistic? Effects of sociodemographic factors, individual experiences and peer characteristics on optimism in early adolescents. Journal of Personality, 87, 661-675. doi: 10.1111/jopy.12424. 


\begin{abstract}
Objective: Although a growing body of research has confirmed the manifold advantages of being an optimist, only a limited body of previous research has addressed the antecedents of optimism in real-life situations. This study examined whether parental socioeconomic status (SES), age-salient experiences (i.e., doing well in school and perceiving acceptance from peers), and aspects of the student composition at school contribute to changes in the optimism of early adolescents.
\end{abstract}

Method: We followed a large sample of German $7^{\text {th }}$ graders $(N=7272 ; 52.9 \%$ females; baseline $\left.M_{\mathrm{age}}=14.1\right)$ at two measurement points over a period of five months and estimated latent regression models.

Results: First, optimism showed medium-sized rank-order stability between both measurement points. Second, the parental SES predicted changes in optimism, but this effect was fully mediated by age-salient experiences. Third, positive age-salient experiences, i.e., academic achievement and perceived peer acceptance, predicted positive changes in early adolescents' optimism. Fourth, our results suggested no effects of school peer composition.

Conclusion: The findings broaden our current knowledge about antecedents of changes in optimism during early adolescence by highlighting the effects of positive age-salient experiences, namely academic achievement and perceived acceptance from peers.

Keywords: optimism, adolescence, academic achievement, peer acceptance, parental SES. 
Why are you so optimistic? Effects of sociodemographic factors, individual experiences, and peer characteristics on optimism in early adolescents

Optimists seem to outperform their less optimistic peers in various areas of life. Over the last decades, research has repeatedly confirmed the beneficial effects of generalized positive expectations: Optimism is associated with greater well-being and better interpersonal relationships, physical health, and educational and occupational outcomes (Carver, Scheier, \& Segerstrom, 2010; Segerstrom, 2007; Tetzner \& Becker, 2017). Moreover, optimists experience lower levels of distress and are more successful in coping with stressful situations (Kivimäki et al., 2005; Robinson \& Liu, 2013; Tetzner \& Becker, 2015). Given these all-round advantages, an important question concerns why some people are more optimistic than others and, in extenso, how optimism can be acquired and promoted. Although a broad range of literature and programs have focused on ways to enhance optimistic expectations (Beck, 1976; Meevissen, Peters \& Alberts, 2011, Seligman, 2006), only a limited body of previous research has addressed the antecedents of optimism in real-life situations. Consequently, little is known about whether different experiences and factors influence its development. The present study aimed to address this issue using a large prospective German study of early adolescents.

\section{Stability and Change of Optimism During Adolescence}

Optimism reflects individual differences in whether people expect good (or bad) things to happen to them (Carver et al., 2010). It therefore not only refers to thoughts about the individual's ability to control future outcomes but also encompasses positive expectations about factors that lie outside the person's own control (Bandura, 2006; Rand, 2009). Optimism is mainly conceptualized as a trait showing considerable stability and consistency across time and contexts (Carver et al., 2010; Costa \& McCrae, 1994). However, its test-retest correlations 
usually lie between .58 and .79 over time periods up to three years (Carver et al., 2010; Atienza et al., 2004; Scheier, Carver \& Bridges, 1994) and therefore reflect potential for both stability and change. Moreover, optimism seems to be less genetically based than other personality traits. Twin studies have reported heritability estimates around 25 percent for optimism (Plomin et al., 1992), whereas researchers have estimated the genetic influence on personality traits at between 30 and 50 percent (Plomin, DeFries, Knopik, Neiderhiser, 2016; for the Big Five personality traits between 41 and 61 percent; Jang, Livesley, \& Vernon, 1996). Thus, optimism may be particularly prone to environmental influences (Segerstrom, 2007). The idea that contexts considerably shape optimism also matches a social-cognitive perspective stating that personality characteristics and related behaviors are not primarily genetically based but rather emerge from cognitive processes that can be modified by environments (Bandura, 1999).

Accordingly, optimism seems to be less stable during stages that are characterized by substantial transitions in life circumstances and environments (Carver et al., 2010; Costa \& McCrae, 1994). Segerstrom (2007) investigated optimism in American first-year law students and again 10 years later and found a long-term stability of only .35. She speculated that the young age and the fundamental changes during emerging adulthood (cf. Arnett, 2000) contributed to the low stability in this sample. It is therefore conceivable that optimism may also change considerably during adolescence when individuals likewise experience extensive challenges and changes, i.e., identity development and maturation processes (Hill \& Edmonds, 2017; Masten, Obradovic, \& Burt, 2006). Accordingly, the BIJU-data confirmed a five-month rank-order stability of only .33 in early adolescents who had recently transitioned from primary to secondary schooling (Tetzner \& Becker, 2017). To date, it is largely unknown which factors contribute to changes in adolescents' optimism. However, knowing more about optimism's 
antecedents may be especially important for this crucial life period when individuals establish expectations for their futures and set the course for their lives (Brissette, Carver \& Scheier, 2002).

\section{The Role of Parental Socioeconomic Resources}

Previous attempts to explain changes in optimism have argued for a resource-oriented view (Segerstrom, 2007). The idea is that individuals who have more resources at hand also have more reason to expect positive outcomes in their futures than those with fewer resources, mainly because these resources help them to reach their goals and make them feel better protected and prepared in the case of failure. In particular, early experiences can serve as resources and influence optimism (Heinonen et al., 2006; Korkeila et al., 2004).

Research has therefore highlighted the role of socioeconomic conditions during childhood (Boehm, Williams, Ryff, \& Kubzansky, 2015; Heinonen et al., 2006; Korkeila et al., 2004). Beneficial socioeconomic circumstances such as high household income, smaller household size, and high parental education are generally associated with a high number of environmental resources, such as an advantageous parenting style or financial resources, which promote adaptive functioning (Benner, Boyle \& Sadler, 2016; Hackman \& Farah, 2009; Hoff, Laursen, \& Tardif, 2002). Heinonen and colleagues (2006) found that parental socioeconomic status during childhood (SES; aggregated from occupational status, educational level, and employment status) predicted optimism in adulthood 21 years later. Individuals who moved upward in their own adult SES compared to their parents' SES still showed lower optimism than those who moved downward. Thus, their results highlighted the long-lasting detrimental effects of low parental SES during childhood. Similarly, Korkeila and colleagues (2004) indicated that persons who suffered childhood adversities such as long-term financial difficulties in the family reported less 
optimistic expectations in adulthood. Other studies confirmed relations between parents' educational level or occupational status and the optimism of their offspring (Daraeei \& Ghaderi, 2012; Ek, Remes \& Sovio, 2003). In summary, this line of research suggested that early socioeconomic resources build a foundation for the development of optimism.

\section{The Role of Individual Experiences During Adolescence}

However, less is known about whether experiences that individuals undergo during their developmental progression continue to modify their optimism. A useful framework to study such developmental changes is the developmental task approach (see Hutteman, Hennecke, Orth, Reitz, \& Specht, 2014). Havighurst (1972) defined age-salient tasks for each period of life that arise from societal expectations, physical processes, and personal goals. Age-salient tasks during adolescence include doing well in school and building up positive relationships with peers (Masten et al., 2006). How well adolescents perform academically affects what opportunities will be open to them (Spinks et al., 2007). Similarly, peer relations gain in importance during adolescence and influence how individuals behave and what they feel and think (James, 1890; Brown, 2011; Harter, 2012; Reitz et al., 2014). Age-salient tasks serve as role expectations for individuals' behavior and the accomplishment of these tasks provides resources for future developments (Roisman, Masten, Coatsworth, \& Tellegen, 2004; Spinks et al., 2007). Accordingly, stressors that come up as individuals seek to fulfill social roles can diminish optimism (Atienza et al., 2004). Similarly, self-determination theory (Deci \& Ryan, 2000) states that perceiving social belonging and competence in valued domains constitute psychological needs that evoke psychological well-being. Building on these assumptions, doing well in school and feeling accepted by peers may provide a foundation for adolescents to envision a positive future and boost their optimism. 
Longitudinal research on effects of academic and social resources on optimism is scarce and just a few studies have targeted adolescents. However, some cross-sectional studies provide first evidence for connections (Ek et al., 2003; Orejudo, Puyuelo, Fernandez-Turrado, \& Ramos, 2012). In investigating English students, Dewberry and Richardson (1990) found academicallyrelated stress and anxiety associated with lower optimism. Orejudo and colleagues (2012) investigated effects of family and peer group variables on optimism in junior high school students. Their results indicated relations between positive peer experiences and higher optimism, whereas negative peer experiences were associated with lower optimism. In this study, results differed slightly by gender. A recent prospective study has already confirmed an association between early adolescents' academic achievement and subsequent changes in their optimism (Tetzner \& Becker, 2017). To the best of our knowledge, no previous study has investigated longitudinal effects of peer relationships on adolescents' optimism. However, research has suggested more optimistic expectations in individuals who experience better relationships with their parents during childhood (Korkeila et al., 2004).

Studies that used adult samples have also reported indications for influences of academic and social experiences. Atienza and colleagues (2004) found that problems at work predicted decreasing optimism scores in adult women. Rosenstreich and colleagues (Rosenstreich, Feldman, Davidson, Maza \& Margalit, 2015) reported lower optimism among first-year college students with learning disabilities compared to those without learning disabilities. Segerstrom (2007) investigated whether resource growth influences the optimism of graduates from law school and suggested that increases in social networks (i.e., a higher number of friends) predicted subsequent increases in optimism. However, she did not found an optimism-boosting effect of a 
higher income. Since this study targeted a group with a relatively homogeneous income, it is unclear whether these results are generalizable to more heterogeneous samples.

In summary, the small existing empirical evidence suggests that positive experiences regarding school achievement and peer relationships enhance early adolescents' optimism. Studies likewise indicate long-lasting effects of parental SES. However, both predictors, parental SES and the educational and social success of the offspring, are also strongly related (Benner et al., 2016; Sirin, 2005). Thus, it is not clear to what extent socioeconomic conditions or the individual's experiences and achievements exert a more powerful influence on early adolescents' optimism. To the best of our knowledge, no previous study has examined the effects of parental SES and academic and social resources on optimism simultaneously.

Relatedly, an additional open point concerns what kind of experiences, more distal or more proximal ones, influence optimism more strongly. Researchers have used different achievement indicators, such as achievement recordings, school track attendance, and cognitive abilities, to investigate associations with students' developmental outcomes (Masten et al., 2005; Strenze, 2007). Although these indicators are undoubtedly highly correlated, they differ in whether they directly refer to adolescents' experiences or whether they rather reflect structural conditions or antecedents of academic behavior. We hypothesize that, for influencing optimism, more experience-based measures, such as achievement test scores, exert a stronger and more direct influence than more distal measures, such as cognitive abilities and school track attendance.

\section{The Role of the Peer Environment}

Research has also emphasized contexts for shaping developmental processes (Bronfenbrenner, 1979). During adolescence, youth increasingly pursue independence from their 
parents, and other social contexts, such as the school context, gain in importance (Eccles et al., 1993). An additional question therefore concerns whether positive characteristics of their school environments also serve as resources for optimism. Besides institutional and instruction-related characteristics, peer composition, such as the quality of peer relationships or shared attitudes, beliefs, and values, constitutes an important aspect of adolescents' school environment (Cohen, McCabe, Michelli, \& Pickeral, 2009; Thapa, Cohen, Guffey, Higgins-D’Alessandro, 2013). For adolescents' optimism, relevant compositional characteristics may comprise a high level of optimism in the peer group but may also include a positive social climate or educational resources. Several theoretical approaches give hints of such composition effects.

The concept of (peer) contagion proposes that persons in social relationships or in one peer group unconsciously transmit characteristics, especially emotional expressions, between each other and converge emotionally (Dishion \& Tipsord, 2011; Hatfield, Cacioppo, \& Rapson, 1994). Peer contagion effects exist for different socio-emotional characteristics in adolescents, such as deviant behavior or aggression (Dishion \& Tipsord, 2011). Although researchers have highlighted the topic of positive peer contagion as a promising direction for future research, no previous study has investigated those effects regarding optimism. Nevertheless, peer contagion effects have been confirmed for negative attributional styles (Prinstein, 2007). In a similar manner, Rius-Ottenheim and colleagues (2012) reported associations between parents' optimistic expectations and the optimism of their children in two samples. Given these assumptions, it seems likely that the level of optimism in the classroom may influence the individual level of optimism.

Research on school climate also states that the school environment exerts a considerable influence on students' scholastic and psychosocial development (Cohen et al., 2009; Ellis, 1988; 
Pekrun, 1985). A favorable peer composition, such as generally positive social relationships or an academically high-achieving class composition may provide resources for individual developments. High-achieving classrooms are characterized by a high degree of academic orientation, motivation, and engagement (Trautwein, Lüdtke, Marsh, Köller, \& Baumert, 2006). Positive peer relationships enable greater access to information and support (Wentzel, 2014). Hence, the academic and social peer composition may provide resources that influence adolescents' optimism.

Conversely, diminishing effects on optimism in high-achieving peer groups are also conceivable. The big-fish-little-pond-effect (BFLPE) describes the phenomenon that students in high-achieving classrooms usually express lower perceptions regarding their own academic achievement than students in lower-achieving classrooms (Marsh, 1987; Marsh, Seaton et al., 2008). This tendency to base self-perception on a reference group may also lead to lower optimism in adolescents who compare their own resources with those of a more privileged peer group (cf. Nagengast \& Marsh, 2012).

In summary, there are conceivable effects of the school peer composition on early adolescents' optimism. However, to the best of our knowledge, no previous study has addressed this potentially important issue.

\section{The present study}

The purpose of this study was to examine antecedents of changes in optimism during the crucial life period of early adolescence. To this end, we followed a large sample of German $7^{\text {th }}$ graders from a range of schools in four German states in two waves over five months. In focusing on changes in optimism from a resource-oriented perspective (Segerstrom, 2007), we used a comprehensive framework that incorporated potential predictors on the individual and 
contextual level. As a basis for our research questions, we first aimed to replicate findings on considerable changes in optimism during early adolescence (Tetzner \& Becker, 2017). With the objective of addressing the gaps outlined above, this study had three main purposes:

Aim 1 was to examine the effects of parental SES. Building on previous research that highlights the role of early socioeconomic conditions for the development of optimism (e.g., Heinonen et al., 2006), we expected to find a higher parental socioeconomic background associated with higher levels of optimism in early adolescents.

Aim 2 was to investigate the influence of individual academic and social experiences on optimism. On the one hand, we expected to find positive experiences in both domains associated with increases in early adolescents' optimistic expectations, and we expected that negative experiences would lower their optimism. We based this expectation on theoretical assumptions regarding the developmental significance of academic achievement and peer relationships (Havighurst, 1972; Deci \& Ryan, 2000) and on first empirical findings indicating their effects on optimism (Orejudo et al., 2012; Tetzner \& Becker, 2017). On the other hand, we expected to find that individual experiences may, at least partially, mediate the influence of parental SES on optimism. Due to the fact that parental SES and social and academic outcomes are strongly related (Benner et al., 2016), they should share at least parts of their predictive power regarding optimism. In a similar manner, we expected that more immediate experiences, such as academic performance and perceived peer acceptance, would influence optimism more directly than more distal resources, such as cognitive abilities or being on a high-achieving school track.

Aim 3 was to examine whether differences in the peer composition (i.e., on the school level) regarding optimistic expectations, peer acceptance, and academic achievement affect individual levels of optimism. Building on research on peer contagion effects (Dishion \& 
Tipsord, 2011) and on effects of a positive school climate (Thapa et al., 2013), we expected to find that high levels of optimism and acceptance in the peer group may act as resources for early adolescents' optimism. Since reference group effects indicate that being in a high-achieving class can diminish students' self-evaluations (Marsh et al., 2008), we treat it as an open question whether a high-achieving student composition may enhance or lower optimism.

Following previous research that indicated gender differences in effects on optimism (Orejudo et al., 2012), we, finally, tested whether our results equally apply to different groups, namely across gender and immigrant status.

\section{Method}

\section{Participants}

This study used a subset of data from the German longitudinal study "Learning Processes, Educational Careers and Psychosocial Development in Adolescence and Young Adulthood” (BIJU; see Schnabel, Alfeld, Eccles, Köller, \& Baumert, 2002 for details), which investigated educational and psychosocial development from early adolescence up to young adulthood in four German states. Data for the present study was collected from students halfway through the $7^{\text {th }}$ grade $\left(t_{1} ;\right.$ Winter 1992) and five months later at the end of the $7^{\text {th }}$ grade $\left(t_{2} ;\right.$ Summer 1992). For our analyses, we used participants with optimism data at $\mathrm{t} 1$ or $\mathrm{t} 2$. This resulted in a sample of $N$ $=7,272$ early adolescents (female students $=52.9$ percent) from 205 schools $(47.4$ percent in the academically-oriented track of Germany’s multi-track system of secondary education and 52.6 percent in non-academically-oriented school tracks). The number of participants per school averaged $M=35.47$ persons $(S D=13.41$; range: $4-76)$. Participants came from different educational (61.5 percent of parents [father and/or mother] with at least a high school diploma) and socioeconomic backgrounds (highest SES of parents: $M=49.19, S D=12.13$; Treiman- 
Index, Treiman, 1977). 7.3 percent of the participants had a migration background (measured by foreign nationality).

\section{Instruments}

Optimism. Optimism was measured by self-ratings of the four items of the positively keyed subscale of the Life Orientation Test (LOT; Scheier \& Carver, 1985; German translation by Wieland-Eckelmann \& Carver, 1989; example item: "In uncertain times, I usually expect the best"; $\left.\alpha_{t 1}=.70, \alpha_{t 2}=.74\right)$ on a five-point Likert scale $(1=$ strongly disagree, $5=$ strongly agree $)$.

Academic Achievement. We assessed academic achievement at t 1 by using standardized achievement tests in mathematics, English, biology, and physics scaled on a common metric using a unidimensional Rasch model (for further information, see Becker, Lüdtke, Trautwein, Köller, \& Baumert, 2012). The tests were designed using tasks from a variety of studies on scholastic achievement so as to produce the best curricular fit possible. To solve the problem of differences in the curriculum and level of achievement in mathematics between different types of secondary schools, the tests were adapted to include items specific to the type of school in which they were used. The reliabilities of the test scores ranged between $\alpha_{t 1}=.66$ and $\alpha_{t 1}=.88$.

Peer Acceptance. We assessed peer acceptance at t1 using a set of three items (Fend \& Prester, 1986; example item: “When the others do something together at recess, they often don't include me"; $\left.\alpha_{t 1}=.79\right)$ on a four-point Likert scale $(1=$ strongly disagree, $4=$ strongly agree $)$. Although our scale only used inverted negatively keyed items, we proved the validity of the measure by establishing scale consistencies with an additional positively keyed item at another measurement point in the study (see Tetzner, Becker \& Maaz, 2017).

Socioeconomic status. We measured parental socioeconomic background using the Treiman Index (Treiman, 1977). Based on information from students about their parents' 
occupations, we coded the occupational prestige for mothers and fathers separately, with higher scores indicating higher educational prestige (fathers: $M=44.35, S D=12.91$, range: 18.10 78.90; mothers: $M=43.37, S D=12.62$, range: $14.40-78.90$ ). To reduce the amount of missing data, we combined information from three assessments in $7^{\text {th }}$ grade (beginning, mid-term, and end of the school year).

Cognitive Abilities. We assessed cognitive abilities using the figure analogies and verbal intelligence subscales of the Kognitiver Fähigkeitstest (KFT 4-13+; Heller, Schoen-Gaedike, \& Weinlaeder, 1985), a slightly adapted German version of Thorndike's Cognitive Abilities Test (Thorndike \& Hagen, 1971) administered at the beginning of the $7^{\text {th }}$ grade (for further information, see Becker et al., 2012).

\section{Statistical Approach}

Missing Data. For our analyses, we focused on participants with optimism data at $\mathrm{t} 1$ or $\mathrm{t} 2$ $(N=7272)$. The missing data in the other variables averaged 22.7 percent. In such cases, the current literature recommends replacing missing values using multiple imputation (MI, cf. Graham, 2009; Little \& Rubin, 2002). Although MI does not rule out parameter bias entirely, it maximizes test power and reduces the risk of biased parameter estimations, in particular in combination with auxiliary variables (cf. Collins, Schafer, \& Kam, 2001). We carried out MI using the MICE package (Multiple Imputation by Chained Equations; van Buuren \& GroothuisOudshoorn, 2011) in the R 3.3.1 software (cf. R Core Team, 2016). We imputed and summarized five datasets according to Rubin's (1987) rules, which can be implemented automatically in Mplus using the analysis option type = imputation (Muthén \& Muthén, 1998-2013).

Analytical Strategy. We estimated multivariate latent regression models to test our research questions (see Figure 1). As a basis for all further analyses, we specified a structural 
model for optimism across both measurement points with one latent factor for each point and stepwise tested measurement invariance. We evaluated the fit of our models using multiple model fit indices: the root mean square error of approximation (RMSEA), the comparative fit index (CFI), and the standardized root mean square residual (SRMR). CFIs above .90 and RMSEAs and SRMRs below .08 typically indicate an acceptable fit with the data (SchermellehEngel, Moosbrugger, \& Müller, 2003). Since we can assume strict factorial invariances over time (as factor loadings, measurement intercepts, and residual variances were constrained to be equal across time points; see Meredith, 1993; RMSEA $=.045, \mathrm{CFI}=.967, \mathrm{SRMR}=.033$ ), our results are relatively independent of random measurement error and of changes in measurement across time (Bollen \& Curran, 2006). By the same token, we allowed for correlated residuals of the corresponding manifest items across adjacent time points (Bollen \& Curran, 2006).

To address our research questions, we successively added predictors for optimism at t 2 to the model. All our models controlled for prior levels of optimism at $t 1$ and for the influence of gender and migration status as control variables. First, we investigated whether parental SES predicted changes in optimism between $\mathrm{t} 1$ and $\mathrm{t} 2$ (aim 1). To investigate the influence of academic and social experiences (aim 2), we secondly added children's cognitive abilities and their school track (academically-oriented track vs. non-academically-oriented track) as more distal predictors, and thirdly added academic achievement and perceived peer acceptance at $\mathrm{t} 1$ as more experience-related predictors to the model. Fourth, we investigated the effects of schoollevel predictors (aim 3; average level of optimism, average academic achievement, and average perceived peer acceptance). Therefore, we tested a series of models by estimating the influence of each school-average-level predictor separately as well as estimating a model with all of them simultaneously. We also re-estimated all models by restricting our analyses to schools with data 
for at least 20 students per school $(N=6857$ from 174 schools $)$. All of these analyses produced the same pattern of results.

Finally, we tested the robustness of our findings across different groups, namely gender (boys vs. girls) and immigrant status (immigrant background vs. German citizenship). We estimated a series of multi-group analyses for both comparisons. In each case (i.e., model 1-4), we compared a model that allowed the tested regression paths to vary between groups with a more restrictive model in which we constrained regression paths to be equal between groups. We held measurement invariance between groups constant in all models. Since the chi-square difference test shows increased sensitivity with large sample sizes (Bentler \& Bonet, 1980), we mainly used the Bayesian Information Criterion (BIC) to compare the relative fit of the models, with lower scores typically indicating a better fit to the data.

We used the software package Mplus 7.1 (Muthén \& Muthén, 1998-2013) for structural equation modeling. We accounted for the hierarchical data structure by estimating the models with robust standard errors using the analysis option type $=$ complex (using school as a cluster variable).

\section{Results}

Table 1 shows descriptives and correlations for all constructs under examination and for both measurement points. Overall, these first results showed almost no mean-level changes in optimism between $\mathrm{t} 1$ and $\mathrm{t} 2(d=0.14 ; p>.05)$ and a five-month rank-order stability of .351 , suggesting a certain amount of stability but also change. They also suggested that optimism correlated slightly negatively with gender and immigration status, indicating lower optimism in males and adolescents with an immigrant background. Most importantly and as hypothesized, these first results showed substantial small- to medium-sized correlations between optimism and 
all analysis variables indicating a higher level of optimism in adolescents with higher parental SES, higher cognitive abilities, and higher academic achievement. These results also indicate a higher level of optimism in students that perceive themselves to be better accepted by their peers and in those who attend an academically-oriented school track or a school composed of students who are highly optimistic, high-achieving, or confident that their peers accept them. To examine the developmental significance of these associations during early adolescence more thoroughly, we report standardized results from multivariate latent regression models in the next sections.

\section{Multivariate Predictors of Optimism}

Table 2 shows the results for the stepwise examination of predictors for changes in optimism. In a first step (model 1), we investigated the effect of parental SES on optimism at t2 and found a small-sized positive effect $(b=.10, p<.001)$ even after controlling for optimism at t1. In model 2, we added school track attendance and cognitive abilities as predictors. The results indicated that both being on an academically-oriented school track $(b=.09, p<.05)$ and having higher cognitive abilities $(b=.08,<.05)$ predicted increases in early adolescents' optimism with small-sized effects. Accounting for these associations, we no longer found a statistically significant longitudinal effect of parental SES. A third step appended the influence of individual experiences during adolescence, namely academic achievement and perceived peer acceptance, and suggested that higher academic achievement at $\mathrm{t} 1$ promoted adolescents' optimism with a small- to medium-sized effect $(b=.20, p<.001)$, whereas perceived peer acceptance increased optimistic expectations with a small-sized effect $(b=.08, p<.001)$. None of the other constructs (parental SES, school track, cognitive abilities) predicted optimism incrementally after accounting for these influences. 
In a fourth step, we examined the additional effect of school-level peer characteristics on optimism by adding optimism, academic achievement, and perceived peer acceptance at the school level to our model. Our results indicated that none of these predicted changes in optimism over and above the other predictors in the model. To exclude the possibility that confounded variance between school level predictors prevented us from identifying effects of isolated predictors, we estimated additional models that included each of them separately. These models also indicated no effects (for details see Table S1, models 1-3, in the Supplemental Material). For the sake of completeness, we also checked whether parental SES and cognitive abilities at the school level influence individual changes in optimism but also found no statistically significant association (see Table S1, models 4 and 5, in the Supplemental Material).

\section{Robustness Analyses}

Finally, we tested whether the reported results apply equally to different groups, namely across gender and immigrant status (for exact results see Table S2 in the Supplemental Material). Multiple group analyses revealed no differential relations for gender (see Table S2: grouping a, models 1-4) or immigrant status (see Table S2: grouping b, models 1-4).

\section{Discussion}

The purpose of the present study was to examine factors associated with optimism during early adolescence. To this end, we investigated whether parental SES, age-salient experiences (i.e., academic achievement and perceived peer acceptance), and aspects of the student composition in the school contribute to changes in optimism. Targeting a large prospective German sample, this study is the first to use a comprehensive framework to address individual and contextual predictors of optimism during adolescence simultaneously. 
To start, we aimed to replicate findings regarding considerable changes in optimism during early adolescence. Indeed, analyses revealed a medium-sized rank-order stability of only .33 over five months. This contradicts previous studies that reported test-retest correlations between .58 and .79 over time periods up to three years (Carver et al., 2010; Atienza et al., 2004; Scheier et al., 1994). However, it is in line with considerations that optimism may be less genetically based than other personality traits and especially prone to environmental influences (Plomin et al., 1992), as well as replicated research that found optimism to be less stable during transitional life periods (Segerstrom, 2007), such as early adolescence (Tetzner \& Becker, 2017). One explanation is that the extensive challenges and changes during adolescence, such as identity development, maturational processes, and the transition from primary to secondary school (Hill \& Edmonds, 2017; Masten et al., 2006) include a host of positive and negative experiences and influence individuals' future expectations. Since a tremendous body of research has confirmed that adolescence is a crucial life period in which individuals set the course for their future lives and that optimism influences how they deal with those challenging situations (Carver at al., 2010; Roisman et al., 2004), changes in optimism during adolescence may have especially long-lasting implications. Therefore, this study underscores the need to examine more thoroughly the factors that contribute to those changes.

The first aim of this study was to examine whether parental SES contributes to changes in adolescents' optimistic expectations. Drawing on assumptions that socioeconomic resources enhance optimism (Heinonen et al., 2006), we expected to find adolescents with more socioeconomic resources at hand to be more optimistic than those with fewer socioeconomic resources. Our results confirmed this assumption by showing a positive association between parental SES and adolescent optimism. This is in line with previous research that also suggested 
that favorable socioeconomic conditions during childhood built a basis for optimism (Heinonen et al., 2006; Korkeila et al., 2004; Daraeei \& Ghaderi, 2012). One possible mechanism is that financial resources and accompanying advantages, such as a favorable parenting style, directly contribute to a more optimistic outlook. However, another possibility is that high SES promotes adolescents' optimism more indirectly by enabling a higher probability of success in important areas of life, such as higher cognitive abilities and school performance, the opportunity to attend an academically-oriented school track, or more positive social relationships.

To address this so far unexplored issue, the second aim of this study was to examine whether age-salient experiences influence early adolescents' optimism and whether these associations may, at least partly, mediate the effects of parental socioeconomic resources on optimism. To the best of our knowledge, this study was the first to examine the effects of parental SES and academic and social resources on optimism simultaneously. Drawing on assumptions that resource changes may influence optimism (Segerstrom, 2007) and that doing well in school and building up peer relationships constitute important age-salient tasks for adolescents that provide resources for future development (Roisman et al., 2004), we expected to find positive academic and peer experiences associated with increases in optimism. Indeed, results revealed a considerable influence of those age-salient experiences on optimism. This is in line with some cross-sectional (e.g., Dewberry \& Richardson, 1990) and first longitudinal research (Tetzner \& Becker, 2017) that already indicated that positive academic experiences enhance adolescents' optimism. To the best of our knowledge, no previous prospective study has provided evidence for the influence of positive peer experiences on optimism.

This study extended previous research by revealing three additional results. First, parental SES no longer showed influence on early adolescents' optimism after we accounted for 
academic and social experiences. Second, more immediate experiences, i.e., performing well at school and perceiving social acceptance from peers, exerted a more powerful influence than more distal experiences, i.e., attending a high-achieving school track or having greater cognitive abilities. Third, this pattern of results was robust and applied to boys and girls as well as to adolescents with and without an immigrant background. Our findings therefore underscore the importance of positive experiences for developing optimistic expectations. One explanation may be that individuals mostly base their expectations regarding future success on behavior-related experiences, rather than on preconditions. Although more favorable starting conditions such as better familial socioeconomic conditions or higher cognitive abilities enhance the probability for success (e.g. Sirin, 2005; Strenze, 2007) and should therefore facilitate a more optimistic outlook, adolescents seem to relativize their optimistic expectations based on how successfully they manifest these starting conditions in their present experiences. Building on an individual and genetically determined level of optimism (Plomin et al., 1992), adolescents seem to bring their expectations regarding future success in line with previous experiences in salient areas and modify their expectations when new experiences are available.

The third aim of the study was to examine whether conditions in adolescents' peer environments also influence their optimism. Building on assumptions about the importance of environmental influences, and especially the school context during adolescence (Eccles et al., 1993), and on more specific theories regarding peer contagion (Dishion \& Tipsord, 2011) and school climate effects (Cohen et al., 2009), we expected that more optimistic expectations and positive peer relationships in early adolescents' peer environments would predict higher individual optimism. We set no specific assumption regarding the influence of high achievement at the school level because negative effects also seemed to be reasonable (Marsh et al., 2008). 
For the sake of completeness, we also investigated effects of school-average SES and cognitive abilities. Contrary to our assumptions, our analyses suggested that the composition factors under investigation do not influence early adolescents' optimism. To the best of our knowledge, no previous study examined effects of the peer composition on early adolescents' optimism, and our study provided first hints on these effects. Nevertheless, several explanations are conceivable. On the one hand, the results may indicate that early adolescents do not orient their future expectations based on their environments. Hence, this finding may strengthen the assumption that individual experiences exert the most important influence on optimistic expectations. On the other hand, our study investigated effects in a broader context (i.e., school level) and it may be the case that optimistic expectations are more influenced by nearby peers, such as close friends.

\section{Limitations and Implications for Future Research}

To the best of our knowledge, this study was the first to examine antecedents of changes in optimism during adolescence by focusing on individual and contextual predictors. This approach provided insights into why optimism changes during adolescence and how it may be promoted. This study is an important starting point for future research that may also address some of the limitations of the present study. The first limitation concerns the generalizability of our results. The BIJU-Data involved an oversampling of students in the academically-oriented track of Germany's secondary school system and it may be partly because of this reduction in variability that we found no compositional effects on adolescents' optimism. Moreover, we followed only one cohort of $7^{\text {th }}$ graders. Future research should address whether the effects hold for other samples and age groups.

A second limitation is that we measured changes in optimism over a relatively short time period, i.e. five months. Thus, we cannot clarify whether the changes in optimism are lasting or 
whether the individual level of optimism may bounce back to a biologically determined level over a longer period. For example, this has been shown for subjective well-being (see set-point model, Lucas, 2007). Since our results indicate that individual experiences may shape adolescents' optimism, the stability of these changes may also depend on the continuity of the experiences. Hence, single negative experiences (e.g., a poor grade or a temporary conflict with a friend) may be easily compensated by subsequent positive experiences and less likely to compromise an adolescent's optimism permanently than ongoing negative experiences (e.g. persistent failures at school and social problems with classmates). Hence, future research should address whether changes in optimism remain stable over longer time spans. In a similar vein, future studies should use a more change-sensitive approach and address whether changes in individual experiences (i.e., decreasing scholastic achievement or increasing peer problems) are directly associated with changes in adolescents' optimism.

A second limitation is that we measured the peer compositional effects at the school level. However, research has shown that composition effects at the class level are generally higher than at the school level (van Ewijk \& Sleegers, 2010) and indicated that effects may be moderated by friendship quality, popularity, or peers' status (Prinstein, 2007; Dishion \& Tipsord, 2011). Future research is needed to examine these associations in more detail and to broaden the focus to additional factors in early adolescents' environment. Third, we used the positively keyed subscale of the Life Orientation Test (Scheier \& Carver, 1985) for our analyses. Therefore, our results apply to optimism but do not necessarily provide information about effects on adolescents' pessimism. Relating to the ongoing controversy about whether optimism and pessimism represent one bipolar dimension or two largely distinct dimensions (Carver et al., 2010; Herzberg, Glaesmer, \& Hoyer, 2006), future studies should further examine whether our 
results also apply to adolescents' pessimism. Fourth, our study used standardized achievement scores to measure academic achievement. Although these objective measures constitute useful and valid estimations, more subjective measures, such as school grades, may be more salient and noticeable by adolescents and, therefore, affect their optimistic expectations more directly. Fifth, although our study indicated that positive experiences in the academic and social domains may enhance early adolescents' optimism, we cannot clarify which mechanisms produce these associations. Future research may try to disentangle the underlying mechanisms.

\section{Conclusions}

This study aimed to examine individual and contextual predictors on changes in optimism during early adolescence. The findings showed that - although optimism is supposed to be a personality trait - it is also subject to change. Especially in light of the tremendous body of research confirming the multifaceted advantages of being an optimist, this result underscores the need to investigate the antecedents of changes in optimism more thoroughly. Therefore, this study replicated previous research by indicating that favorable socioeconomic conditions in the family may benefit optimism during adolescence. However, it also broadened the current knowledge about antecedents of changes in optimism by highlighting the effects of positive agesalient experiences, namely academic achievement and perceived social acceptance. It therefore provides starting points for interventions to promote optimism in early adolescents. 


\section{Declaration of conflicting interest}

The authors declared no potential conflicts of interest with respect to the research, authorship, and/or publication of this article.

\section{Funding}

The authors received no financial support for the research, authorship, and/or publication of this article. 


\section{References}

Arnett, J. J. (2000). Emerging adulthood. A theory of development from the late teens through the twenties. American Psychologist, 55, 469-480.

Atienza, A. A., Stephens, M. A. P., \& Townsend, A. L. (2004). Role stressors as predictors of changes in women's optimistic expectations. Personality and Individual Differences, 37, 471484.

Bandura, A. (2006). Adolescent development from an agentic perspective. In F. Pajares \& T. C. Urdan (Eds.), Self-efficacy beliefs of adolescents (pp. 1-44). Greenwich, Conn: IAP Information Age Pub., Inc.

Bandura, A. (1999). Social cognitive theory of personality. In L. A. Pervin \& O. P. John (Eds.), Handbook of personality: Theory and research (2nd ed., pp. 154-196). New York: The Guilford Press.

Beck, A.T. (1976). Cognitive Therapy and the Emotional Disorders. International Universities Press; 1976.

Becker, M., Lüdtke, O., Trautwein, U., Köller, O., \& Baumert, J. (2012). The differential effects of school tracking on psychometric intelligence: Do academic-track schools make students smarter? Journal of Educational Psychology, 104, 682-699.

Benner, A. D., Boyle, A. E., \& Sadler, S. J. (2016). Parental involvement and adolescents' educational success: The roles of prior achievement and socioeconomic status. Journal of Youth and Adolescence, 45, 1053-1064.

Bentler, P. M., \& Bonett, D. G. (1980). Significance tests and goodness of fit in the analysis of covariance structures. Psychological Bulletin, 88, 588-606. 
Boem, J., Chen, Y., Williams, D.R., Ryff, C., \& Kubzansky, L.D. (2015): Unequally distributed psychological assets: are there social disparities in optimism, life satisfaction, and positive affect? PLoS ONE, 10, 1-16.

Bollen, K. A. \& Curran, P. J. (2006). Latent curve models: A structural equation approach. San Francisco, CA: Jossey-Bass.

Brissette, I., Carver, M. F., \& Scheier, C. S. (2002). The role of optimism in social network development, coping and psychosocial adjustment during a life transition. Journal of Personality and Social Psychology, 82, 102-111.

Bronfenbrenner, U. (1979). The ecology of human development: Experiments by nature and design (Vol 2. print, XV). Cambridge, MA: Harvard University Press.

Brown, B. B. (2011). Popularity in peer group perspective: The role of status in adolescent peer systems. In A. H. Cillessen, D. Schwartz, \& L. Mayeux (Eds.), Popularity in the peer system (pp. 165-192). New York, NY: Guilford Press.

Carver, C. S., Scheier, M. F., \& Segerstrom, S. C. (2010). Optimism. Clinical Psychology Review, 30, 879-889.

Cohen, J., McCabe, E. M., Michelli, N. M. \& Pickeral, T. (2009). School climate: Research, policy, practice, and teacher education. Teachers College Record, 111, 180-213.

Collins, L. M., Schafer, J. L., \& Kam, C.-M. (2001). A comparison of inclusive and restrictive strategies in modern missing data procedures. Psychological Methods, 6, 330-351.

Costa, P. T., \& McCrae, R. R. (1994). Set like plaster? Evidence for the stability of adult personality. In T. F. Heatherton \& J. L. Weinberger (Eds.), Can personality change? (pp. 201225). Washington, DC: American Psychological Association. 
Daraeei, M., \& Ghaderi, A.R. (2012). Impact of Education on Optimism/Pessimism. Journal of the Indian Academy of Applied Psychology, 38, 339-343.

Dishion, T. J., \& Tipsord, J. M. (2011). Peer contagion in child and adolescent social and emotional development. Annual Review of Psychology, 62, 189-214.

Deci, E. L., \& Ryan, R. M. (2000). The "what" and "why" of goal pursuits: human needs and the self-determination of behavior. Psychological Inquiry, 11, 227-268.

Dewberry, C., \& Richardson, S. (1990). Effect of anxiety on optimism. The Journal of Social Psychology, 130, 731-738.

Eccles, J., Midgley, C., Wigfield, A., Buchanan, C. M., Reuman, D., Flanagan, C., \& Mac Iver, D. (1993). Development during adolescence: The impact of stage-environment fit on young adolescents' experiences in schools and in families. American Psychologist, 48, 90-101.

Ek, E., Remes, J., \& Sovio, U. (2003). Social and Developmental Predictors of Optimism from Infancy to Early Adulthood. Social Indicators Research, 69, 219-242.

Ellis, T. I. (1988). School Climate. Research Roundup, 4, 1-6.

Fend, H., \& Prester, H.-G. (1986). Dokumentation der Skalen des Projekts „Entwicklung im Jugendalter', [Documentation of the scales used in the project " development in adolescence'’]: Bericht aus dem Projekt. Sozialwissenschaftliche Fakultät der Universität Konstanz

Graham, J. W. (2009). Missing Data Analysis: Making It Work in the Real World. Annual Review of Psychology, 60, 549-576.

Hackman, D. A., \& Farah, M. J. (2009). Socioeconomic status and the developing brain. Trends in Cognitive Science, 13, 65-73.

Hatfield, E., Cacioppo, J. T., \& Rapson, R. L. (1994). Emotional contagion. Studies in emotion and social interaction. Cambridge: Cambridge University Press. 
Havighurst, R. J. (1972). Developmental tasks and education (3rd ed. [newly rev.]). New York, NY: McKay.

Harter, S. (2012). The construction of the self: Developmental and sociocultural foundations (2nd ed). New York, NY: Guilford Press.

Heinonen, K., Räikkönen, K., Matthews, K. A., Scheier, M. F., Raitakari, O. T., Pulkki, L., et al. (2006). Socioeconomic status in childhood and adulthood: Associations with dispositional optimism and pessimism over a 21-year follow-up. Journal of Personality, 74, 1111-1126.

Heller, K., Schoen-Gaedike, A.-K., \& Weinlaeder, H. (1985). Kognitiver Fähigkeitstest: KFT 413+ [Cognitive Abilities Test: KFT 4-13] (2nd ed.). Weinheim, Germany: Beltz.

Herzberg, P. Y., Glaesmer, H., \& Hoyer, J. (2006). Separating optimism and pessimism: A robust psychometric analysis of the Revised Life Orientation Test (LOT-R). Psychological Assessment, 18, 433-438.

Hill, P. L., \& Edmonds, G.W. (2017). Personality development in adolescence. In J. Specht (Ed.), Personality development across the lifespan (pp. 25-38). San Diego: Elsevier

Hoff, E., Laursen, B., \& Tardif, T. (2002). In M. H. Bornstein (Ed.). Socioeconomic status and parenting (second edition). Mahwah, NJ: Erlbaum Handbook of parenting.

Hutteman, R., Hennecke, M., Orth, U., Reitz, A. K., \& Specht, J. (2014). Developmental tasks as a framework to study personality development in adulthood and old age. European Journal of Personality, 28, 267-278.

James, W. (1890). The principles of psychology. New York, NY: Henry Holt and Company Jang, K.L., Livesley, W.J., Vernon, P.A. (1996). Heritability of the big five personality dimensions and their facets: a twin study. Journal of Personality, 64, 577-591. 
Kivimäki, M., Vahtera, J., Elovainio, M., Helenius, H., Singh-Manoux, A., \& Pentti, J. (2005). Optimism and pessimism as predictors of change in health after death or onset of severe illness in family. Health Psychology, 24, 413-421.

Korkeila, K., Kivelä, S. L., Suominen, S., Vahtera, J., Kivimäki, M., Sundell, J., et al. (2004).

Childhood adversities, parent-child relationships and dispositional optimism in adulthood. Social Psychiatry and Psychiatric Epidemiology, 39, 286-292.

Little, R., \& Rubin, D. B. (2002). Statistical analysis with missing data. New York: Wiley.

Lucas, R. E. (2007). Adaptation and the set-point model of subjective well-being: Does happiness change after major life events? Current Directions in Psychological Science, 16, 7579.Marsh, H. W. (1987). The big-fish-little-pond effect on academic self-concept. Journal of Educational Psychology, 79, 280-295

Marsh, H. W., Seaton, M., Trautwein, U., Lüdtke, O., Hau, K. T., O’Mara, A. J. et al. (2008). The big-fish-little-pond effect stands up to critical scrutiny: Implications for theory, methodology, and future research. Educational Psychology Review, 20, 319-350

Masten, A. S., Obradovic', J., \& Burt, K. B. (2006). Resilience in emerging adulthood: Developmental perspectives on continuity and transformation. In J. J. Arnett \& J. L. Tanner (Eds.), Emerging adults in America: Coming of age in the 21st century (pp. 173-190). Washington, DC: American Psychological Association Press.

Masten, A. S., Roisman, G. I., Long, J. D., Burt, K. B., Obradović, J., Roberts, J. M., Boelcke, K., \& Tellegen, A. (2005). Developmental cascades: Linking academic achievement, externalizing and internalizing symptoms over 20 years. Developmental Psychology, 41, 733746. 
Meevissen, Y.M.C., Peters, M.L., \& Alberts, H.J.E.M. (2011). Become more optimistic by imagining a best possible self: Effects of a two week intervention. Journal of Behavior Therapy and Experimental Psychiatry, 42, 371-378.

Meredith, W. (1993). Measurement invariance, factor-analysis and factorial invariance. Psychometrika, 58, 525-543.

Muthen, L. K., \& Muthen, B. O. (1998-2013). Mplus user's guide (7th ed.). Los Angeles, CA: Authors.

Nagengast, B., \& Marsh, H.W. (2012). Big fish in little ponds aspire more: Mediation and crosscultural generalizability of school-average ability effects on self-concept and career aspirations in science. Journal of Educational Psychology, 104, 1033-1053.

Orejudo, S., Puyuelo, M., Fernandez-Turrado, T., \& Ramos, T. (2012). Optimism in adolescence: A cross-sectional study of the influence of family and peer group variables on junior high school students. Personality and Individual Differences, 52, 812-817.

Pekrun, R. (1985). Classroom climate and test anxiety: Developmental validity of expectancyvalue theory of anxiety. In R. Schwarzer, C. D. Spielberger \& H. M. van der Ploeg (Eds.), Advances in test anxiety research (Vol. 4, pp. 147-158). Lisse, The Netherlands: Swets \& Zeitlinger.

Plomin, R., Scheier, M. F., Bergeman, C. S., Pedersen, N. L., Nesselroade, J. R., \& McClearn, G. E. (1992). Optimism, pessimism, and mental health: a twin/adoption analysis. Personality and Individual Differences, 13, 921-930.

Plomin, R., DeFries, J.C., Knopik, V.S., \& Neiderhiser, J.M. (2016). Top 10 Replicated Findings From Behavioral Genetics, Psychological Science, 11, 3-23. 
Prinstein, M.J. (2007). Moderators of peer contagion: a longitudinal examination of depression socialization between adolescents and their best friends. Journal of Clinical Child and Adolescent Psychology, 36, 159-70.

Rand, K.L. (2009). Hope and Optimism: Latent Structures and Influences on Grade Expectancy and Academic Performance. Journal of Personality, 77, 231-260.

R Core Team (2016). R: A language and environment for statistical computing. Vienna, Austria: R Foundation for Statistical Computing.

Reitz, A.K., Zimmermann, J., Hutteman, R., Specht, J., \& Neyer, F.J. (2014). How Peers Make a Difference: The Role of Peer Groups and Peer Relationships in Personality Development. European Journal of Personality, 28, 279-288.

Rius-Ottenheim N, Kromhout, D., von der Mast, R.C., F.G., Geleijnse, J.M., Giltay, E.J. (2012). Dispositional optimism and loneliness in older men. International Journal of Geriatric Psychiatry, 27, 151-159.

Robinson, M. D., \& Liu, T. (2013). Perceptual negativity predicts greater reactivity to negative events in daily life. Personality and Individual Differences, 55, 926-930.

Roisman, G. I., Masten, A. S., Coatsworth, J. D., \& Tellegen, A. (2004). Salient and emerging developmental tasks in the transition to adulthood. Child Development, 75, 123-133.

Rosenstreich, E., Feldman, D.B., Davidson, O.B., Maza, E., \& Margalit, M. (2015). Hope, optimism and loneliness among first-year college students with learning disabilities: a brief longitudinal study. European Journal of Special Needs Education, 30, 338-350.

Rubin, D. B. (1987). Multiple imputation for nonresponse in surveys. New York, NY: Wiley. Scheier, M. F., \& Carver, C. S. (1985). Optimism, coping, and health: Assessment and implications of generalized outcome expectancies. Health Psychology, 4, 219-247. 
Scheier, M. F., Carver, C. S., \& Bridges, M. W. (1994). Distinguishing optimism from neuroticism (and trait anxiety, self-mastery, and self-esteem): A reevaluation of the Life Orientation Test. Journal of Personality and Social Psychology, 67, 1063-1078.

Schermelleh-Engel, K., Moosbrugger, H., \& Müller, H. (2003). Evaluating the fit of structural equation models: Tests of significance and descriptive goodness-of-fit measures. Methods of Psychological Research, 8, 23-74.

Schnabel, K. U., Alfeld, C., Eccles, J. S., Köller, O., \& Baumert, J. (2002). Parental Influence on Students' Educational Choices in the United States and Germany: Different RamificationsSame Effect? Journal of Vocational Behavior, 60, 178-198

Segerstrom, S. C. (2007). Optimism and resources: Effects on each other and on health over 10 years. Journal of Research in Personality, 41, 772-786.

Seligman, M.E.P. (2006). Learned Optimism: How to Change Your Mind and Your Life. New: York: Vintage Books.

Sirin, S. R. (2005). Socioeconomic status and academic achievement: A meta-analytic review of research. Review of Educational Research, 75, 417-453

Spinks, R., Arndt, S., Caspers, K., Yucuis, R., McKirgan, L. W., Pfalzgraf, C., \& Waterman, E. (2007). School achievement strongly predicts midlife IQ. Intelligence, 35, 563-567. doi:10.1016/j.intell.2006.10.004

Strenze, T. (2007). Intelligence and socioeconomic success: A meta-analytic review of longitudinal research. Intelligence, 35, 401-426.

Tetzner, J., \& Becker, M. (2015). How being an optimist makes a difference: The protective role of optimism in adolescent's adjustment to parental separation. Social Psychological and Personality Science, 6, 325-333. 
Tetzner, J., \& Becker, M. (2017). Think Positive? Examining the Impact of Optimism on Academic Achievement in Early Adolescents. Journal of Personality. Online first access.

Tetzner, J., Becker, M. \& Maaz, K. (2017). Development in Multiple Areas of Life in Adolescence: Interrelations between Academic Achievement, Perceived Peer Acceptance, and Self-Esteem. International Journal of Behavioral Development, 41, 704-713.

Thapa, A., Cohen, J., Guffey, S. \& Higgins-D’Alessandro, A. (2013). A review of school climate research. Review of Educational Research, 83, 357-385.

Thorndike, R. L., \& Hagen, E. (1971). Cognitive abilities test. Boston, MA: Houghton Mifflin. Trautwein, U., Lüdtke, O., Marsh, H.W., Köller, O., \& Baumert, J. (2006). Tracking, grading and student motivation: Using group composition and status to predict self-concept and interest in ninth-grade mathematics. Journal of Educational Psychology, 98, 788-806.

Treiman, D. J. (1977). Occupational prestige in comparative perspective. New York: NY: Academic Press.

van Buuren, S., \& Groothuis-Oudshoorn, K. (2011). MICE: Multivariate Imputation by Chained Equations in R. Journal of Statistical Software, 45, 1-67.

van Ewijk, R. \& Sleegers, P. (2010). The effect of peer socioeconomic status on student achievement. A meta-analysis. Educational Research Review, 5, 134-150.

Wentzel, K. R. (2014). Socialization in school settings. In J. Grusec \& P. Hastings (Eds.), Handbook of social development (2nd ed.). New York, NY: Guilford Press.

Wieland-Eckelmann, R., \& Carver, C. (1989). Dispositionelle Angstbewältigungsstile, Optimismus und Bewältigung: Ein interkultureller Vergleich. [Dispositional styles of coping with anxiety, optimism and coping: an intercultural comparison]. Zeitschrift für Differentielle und Diagnostische Psychologie, 11, 167-184. 


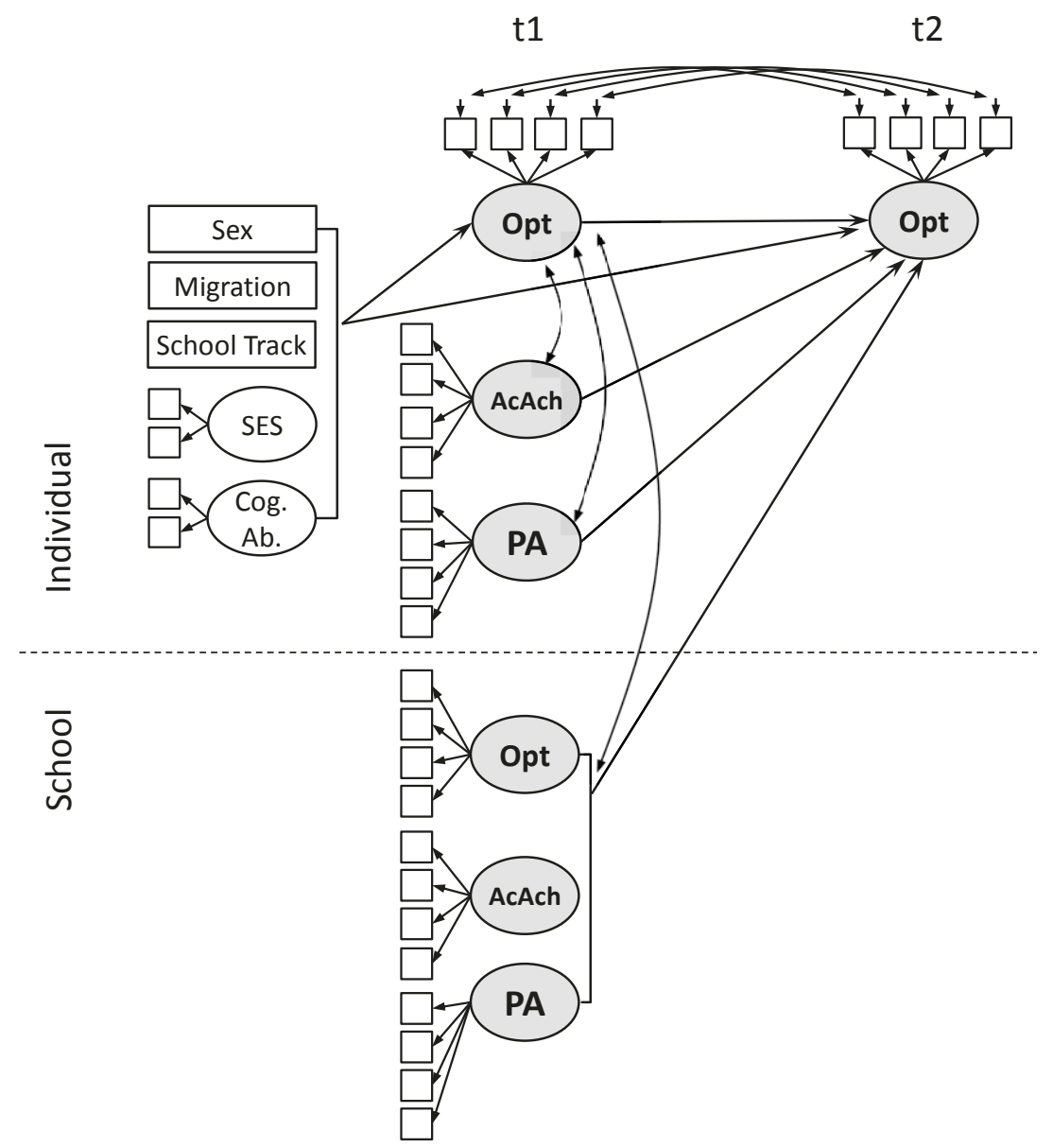

Figure 1. Latent Regression Model.

Note . AcAch = Academic Achievement PA = Peer Acceptance; Opt = Optimism; SES = Parental Socioeconomic Status; Cog. Ab. $=$ Cognitive Abilities. 
Table 1

Mean levels, standard deviations, and correlations.

\begin{tabular}{|c|c|c|c|c|c|c|c|c|c|c|c|c|c|c|c|}
\hline \multicolumn{2}{|c|}{ Latent Construct } & \multirow{2}{*}{$\begin{array}{c}M \\
2.73\end{array}$} & \multirow{2}{*}{$\begin{array}{l}(S D) \\
(0.40)\end{array}$} & \multirow{2}{*}{$\begin{array}{l}\mathrm{ICC} \\
.066\end{array}$} & \multirow{2}{*}{$\begin{array}{l}1 \\
1\end{array}$} & \multirow[t]{2}{*}{2} & \multirow[t]{2}{*}{3} & \multirow[t]{2}{*}{4} & \multirow[t]{2}{*}{5} & \multirow[t]{2}{*}{6} & \multirow[t]{2}{*}{7} & \multirow[t]{2}{*}{8} & \multirow[t]{2}{*}{9} & \multirow[t]{2}{*}{10} & \multirow[t]{2}{*}{11} \\
\hline 1 & Optimism t1 & & & & & & & & & & & & & & \\
\hline 2 & Optimism t2 & 2.67 & $(0.40)$ & - & $.351 * * *$ & 1 & & & & & & & & & \\
\hline 3 & Academic achievement $\mathrm{t} 1$ & -0.29 & $(1.01)$ & .574 & $.222 * * *$ & $.254 * * *$ & 1 & & & & & & & & \\
\hline 4 & Peer Acceptance $\mathrm{t} 1$ & 3.13 & $(0.61)$ & .050 & $.178^{* * *}$ & $.163^{* * *}$ & $.159^{* * *}$ & 1 & & & & & & & \\
\hline 5 & Gender & 0.47 & $(0.50)$ & - & $-.045 *$ & $-.056 *$ & .032 & $-.074 * * *$ & 1 & & & & & & \\
\hline 6 & Migration Status & 0.08 & $(0.27)$ & - & $-.065^{* *}$ & $-.059 *$ & $-.236 * * *$ & -.032 & $.035^{* *}$ & 1 & & & & & \\
\hline 7 & SES & 43.36 & $(8.51)$ & .282 & $.137^{* * *}$ & $.148^{* * *}$ & $.544 * * *$ & $.091^{* * *}$ & .011 & $-.211 * * *$ & 1 & & & & \\
\hline 8 & School track & 1.47 & $(0.50)$ & - & $.179 * * *$ & $.204 * * *$ & $.687 * * *$ & $.150 * * *$ & $-.095^{* * *}$ & $-.158^{* * *}$ & $.560 * * *$ & 1 & & & \\
\hline 9 & Cognitive abilities & 0.37 & $(1.29)$ & - & $.199^{* * *}$ & $.211^{* * *}$ & $.837 * * *$ & $.119^{* * *}$ & $-.072 * *$ & $-.195 * * *$ & $.518^{* * *}$ & $.660 * * *$ & 1 & & \\
\hline 10 & Mean Optimism t1 & 2.74 & $(0.19)$ & - & $.292^{* * *}$ & $.198^{* * *}$ & $.524 * * *$ & $.143^{* * *}$ & $-.062 * *$ & $-.162^{* * *}$ & $.398^{* * *}$ & $.628^{* * *}$ & $.481^{* * *}$ & 1 & \\
\hline 11 & Mean AcAch t1 & -0.28 & $(0.86)$ & - & $.191 * * *$ & $.214 * * *$ & $.801 * * *$ & $.164 * * *$ & $-.072^{* * *}$ & $-.251^{* * *}$ & $.574 * * *$ & $.866^{* * *}$ & $.694 * * *$ & $.667 * * *$ & 1 \\
\hline 12 & Mean PA t1 & 3.13 & $(0.20)$ & - & $.162 * * *$ & $.191^{* * *}$ & $.669 * * *$ & $.127 * * *$ & $-.066 * *$ & $-.184 * * *$ & $.672 * * *$ & $.830 * * *$ & $.625^{* * *}$ & $.583 * * *$ & $.846^{* * *}$ \\
\hline
\end{tabular}

Note. ${ }^{* * *} p<.001,{ }^{* *} p<.01,{ }^{*} p<.05 ; N=7272 ;$ AcAch $=$ Academic Achievement; PA = Peer Acceptance; Opt $=$ Optimism; SES = parental socioeconomic status; school track: $0=$ non-academically-oriented track, $1=$ academically-oriented track; gender: $0=$ female, $1=$ male; migration status: $0=$ immigrant background, $1=$ German citizenship; $\mathrm{ICC}=$ intraclass correlation 
Table 2

Results of the latent regression models predicting optimism at $t 2$.

\begin{tabular}{|c|c|c|c|c|c|c|c|c|c|c|c|c|}
\hline \multirow[b]{2}{*}{ Model Parameters } & \multicolumn{3}{|c|}{ Model 1} & \multicolumn{3}{|c|}{ Model 2} & \multicolumn{3}{|c|}{ Model 3} & \multicolumn{3}{|c|}{ Model 4} \\
\hline & $b$ & $S E$ & $p$ & $b$ & $S E$ & $p$ & $b$ & $S E$ & $p$ & $b$ & $S E$ & $p$ \\
\hline Opt t1 & .332 & .024 & $<.001$ & .315 & .026 & $<.001$ & .295 & .026 & $<.001$ & .295 & .028 & $<.001$ \\
\hline \multicolumn{13}{|c|}{ Sociodemographic factors } \\
\hline SES & .100 & .021 & $<.001$ & .016 & .036 & .658 & .005 & .035 & .895 & .005 & .036 & .878 \\
\hline
\end{tabular}

Individual experiences

distal

School track

$\begin{array}{lllllllll}.086 & .037 & .019 & .026 & .037 & .483 & .065 & .041 & .112\end{array}$

Cognitive abilities

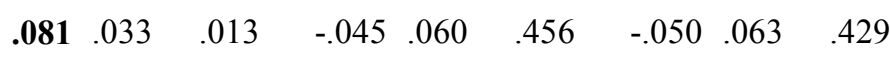

proximal

AcAch t1

$\begin{array}{llllll}.203 & .059 & .001 & .221 & .066 & .001\end{array}$

PA t1

$\begin{array}{lllllll}.077 & .021<.001 & \mathbf{. 0 7 9} & .021<.001\end{array}$

Peer characteristics

Mean Opt t1

$.008 \quad .032 \quad .809$

Mean AcAch t1

$\begin{array}{lll}-.063 & .048 \quad .187\end{array}$

Mean PA t1

$\begin{array}{lll}-.004 & .027 \quad .872\end{array}$

Control variables

Gender

$\begin{array}{lllll}-.041 & .019 & .036 & -.029 & .021\end{array}$

$\begin{array}{lll}.174 & \mathbf{- . 0 4 3} & .020\end{array}$

.031

$\begin{array}{lll}-.045 & .021 & .027\end{array}$

Migration Status

$-.015 \quad .028$

$\begin{array}{llll}584 & -.006 & .027 & 827\end{array}$

$\begin{array}{lll}.009 & .026 \quad .724\end{array}$

$.003 \quad 026 \quad .913$

Model fit indices

$\begin{array}{lllll}\text { CFI } & .952 & .956 & .940 & .924 \\ \text { RMSEA } & .042 & .043 & .036 & .023 \\ \text { SRMR } & .030 & .033 & .034 & .046\end{array}$

Note. $N=7272 ;$ AcAch $=$ Academic Achievement; $\mathrm{PA}=$ Peer Acceptance; $\mathrm{Opt}=$ Optimism; $\mathrm{SES}=$ parental socioeconomic status; school track: $0=$ non-academically-oriented track, $1=$ academically-oriented track; gender: $0=$ female, $1=$ male; migration status: $0=$ immigrant background, $1=$ German citizenship. 